\title{
Molecular Diversity in Predicting Hybrid Performance in Cotton
}

\author{
Somashekhar $^{1 *}$, S. S. Patil ${ }^{2}$ and S. A. Patil ${ }^{2}$ \\ ${ }^{1}$ Plant Breeding, Krishi Vigyan Kendra, Gonikoppal, Kodagu District - 571213, Inida \\ ${ }^{2}$ University of Agricultural Sciences, Dharwad -580 005, India \\ *Corresponding author
}

\section{A B S T R A C T}

\section{Keywords}

Molecular diversity, Hybrid performance, Cotton

\section{Article Info}

Accepted:

22 December 2019

Available Online:

20 January 2020
Cotton (Gossypium spp.) is one of the important commercial crops grown for its natural fibre, which has its own place among many other natural and synthetic fibres. Among the commercial crops grown in India, cotton occupies a pride place of being the prime supplier of raw material $(85 \%)$ for textile industry, which is one of the leading industries in the country. In India, cotton provides means of livelihood for about 60 million people through its cultivation, trade and industrial use. Exploitation of heterosis has lead to improvement in productivity of different crops including cotton. In cross pollinated crops like maize, the hybrid breeding programmes are supplemented by regular systematic improvement programmes aimed at improving combining ability of parents. This has made hybrid development more scientific and purposeful than that based on random crossing of available lines or varieties. Here an effort was made to predict the performance of 52 hybrids derived from two (RAHH 102 and RAHH 136) sets of F4 lines along with their parents (A, B, C and D) were subjected to diversity analysis using RAPD marker system. The actual field performances of the hybrids were correlated with the genetic diversity calculated with the RAPD molecular marker and found insignificant association. This concludes that higher end marker could be utilized for estimating the genetic diversity between Parents.

\section{Introduction}

Morphological features are indicative of the genotype but are represented by only a new locus because they are not large enough. Moreover, they can also be affected by environmental factors and cultural practices. To have an accurate and reliable estimate of genetic relationships and genetic diversity assessment, there is a need of polymorphic molecular markers. Therefore, RAPD technique (Williams et al., 1990) provides unlimited number of marker loci that can be used for genetic diversity and genetic recombination analysis. RAPD markers have been used for the estimation of genetic similarities. To overcome the problems associated with conventional approaches for establishing heterotic groups in a crop, molecular marker based genetic diversity analysis (MMGDA) can remain as an important tool and many have used this to 
predict the hybrid performance (Xiao et al., 1996; Zhang et al., 1994; Liu and Wu, 1998; Zhao et al., 1999).

In rice, inter-group hybrids between $\mathrm{O}$. indica and O. japonica derived lines displayed substantially greater heterosis and F1 yield than intra-group (Xiao et al., 1996). Compared with intra group crosses, the parental genetic distance of inter group crosses, calculated from RFLP or RAPD data, was only moderately increased in maize, but substantially higher in rice. In maize, with genetically balanced sets of crosses, intergroup hybrids out yielded the respective intra -group hybrids by 21 per cent in red yellow dent (RYD)/Lancaster sure crop (LSC) crosses (Dudley et al., 1991) and by 16 percent in Flint $\mathrm{x}$ Dent crosses (Dhillon et al., 1993). In both studies, the percentage of increase in heterosis for yield of inter group over intragroup hybrids was about as large as for hybrid yield itself.

The usefulness of genetic distance as a predictor of hybrid performance has been studied in several crops. In maize (Zea mays L.) and sunflower (Helianthus annuus L.), significant correlations between genetic distance and hybrid performance were observed by Lee et al., (1989), Smith et al., (1990), Lanza et al., (1997) and Cheres et al., (2000). In contrast, Godshalk et al., (1990) and Dudley et al., (1991) observed weak correlations between genetic distance(GD) through markers and hybrid performance in maize .

In cotton correlations between agronomic and fibre traits of $\mathrm{F} 2$ bulk populations and genetic distance of parents were not consistent across environments and sets (Gutierrez et al., 2002). His finding in cotton agree with Melchinger (1993) who concluded that GD estimates based on markers randomly arranged across the maize genome were of no value in predicting hybrid performance. Genetic diversity analysis among recombinants from cross between Jayadhar x BCS 23 was carried out by Soregaon (2004) using nine primers. On an average 78.26 per cent polymorphism was observed and the presence of higher genetic diversity was evidenced by higher range of genetic similarity indices.

\section{Materials and Methods}

The two (RAHH 102 and RAHH 136) sets of F4 lines along with their parents (A, B, C and D) were subjected to diversity analysis using RAPD marker system. The individual plant DNA was analyzed in comparison to the rest. The DNA was extracted from the recombinant lines and their parental genotypes by following CTAB extraction method (Saghai-Maroof et al., 1984) with required modifications. One or two fresh young leaves (not fully expanded and less than a week old) from shoot apex were harvested and the surface was cleaned with wet paper towel. The sample was ground to fine powder using liquid nitrogen with prechilled pestle and mortar. The concentration of DNA was assessed spectrophotometrically and also by gel electrophoresis using 0.8 per cent agarose with known concentration of uncut DNA. In spectrophotometric analysis, 5 $\mu l$ of DNA sample diluted with TE buffer and volume made up to $3000 \mu \mathrm{l}$ with TE buffer and was subjected to spectrophotometer readings at absorbance of $230 \mathrm{~nm}, 260 \mathrm{~nm}$ and $280 \mathrm{~nm}$. A good DNA preparation generally exhibits the following spectral properties.

A230 $<0.10$, A230/A260 $<0.45$, A280/A260 $<0.55$, or A260/A280 $>1.80$

DNA concentration was calculated using O.D. at $260 \mathrm{~nm}$ with following formula. Concentration of DNA $(\mu \mathrm{g} / \mathrm{ml})=$ O.D. at 260 $\mathrm{x} 50$ To test the quality of DNA, samples 
were run on 0.80 per cent agarose gel in $1 \mathrm{x}$ TAE (Tris Acetic acid EDTA) buffer and stained with ethidium bromide and checked for contamination by RNA (which usually runs ahead) and the DNA was evaluated by comparing it with a standard undigested DNA sample.3.10.3 Requirements for polymerase chain reaction (PCR) Template DNA: Purified genomic DNA (30 ng) of recombinants and their parents were used as template DNA per reaction. Random primers: Commercial kits 'A', 'B', ' $C$ ' and ' $Z$ ' of random decamer primers obtained from Operon Technologies Inc. Alamedas, USA were used. A set of 60 decamer primers from OPA series (20 primers), OPB series (10 primers),OPC series (20 primers) and OPZ series (20 primers) were used to screen the parents of two crosses. As many as 20 primers which showed polymorphism and repeatable pattern were selected. Selected primers were used for RAPD analysis to all the lines involved in the study.

dNTPs: Individual dNTPs, dATP, dGTP, dCTP and dTTP obtained from M/S Bangalore Genei. Pvt. Ltd., Bangalore were used.

Taq DNA polymerase Taq DNA polymerase (3 units per $\square$ ) and 10x Taq buffer were obtained from M/S Bangalore Genei. Pvt. Ltd., Bangalore. Thermal cycler Primus 96 plus supplied by MWG AG Biotech, Auzinger Strasse TA, Ebersberg, Germany was used for cyclic amplification of DNA.

Pair wise genetic similarities (Sij) between genotypes were estimated by DICE similarity coefficient. Clustering was done using the symmetric matrix of similarity coefficient and cluster obtained based on un weighted pair group arithmetic mean (UPGMA) using SHAN module of NTSYS-PC version 2.0 (Rohlf, 1998).

\section{Results and Discussion}

Initially out of 60 primers screened, only 20 primers found to be polymorphic between four parents of two crosses (RAHH 102 and RAHH 136). Genetic diversity and F1 performance Molecular genetic diversity was determined separately between the F4 lines of each set (RAHH 102 and RAHH 136) and the parents of the reciprocal tester. This diversity is correlated with the F1s per se which were derived from the lines of F4 and reciprocal tester. Since reciprocal tester is F1, so the average distance from these parents was taken for correlating with the actual field performance of hybrids. Cluster analysis and Dice similarity coefficients were carried out using NTSYS analysis package. The pairwise similarity coefficient values for the 26 F4 lines along with parents were determined for two populations separately. Based on this, dissimilarity coefficients were determined (Table 1) for both set of F4 lines.

For pop I, overall dissimilarity indices ranged from 39 to 60 per cent. The highest dissimilarity coefficient was noticed between the R-8 (102) and RAHH 136 (T1) with 60 per cent dissimilarity coefficient. The cluster analysis and dissimilarity coefficients revealed that the R-8 (102) line was far distinct to the RAHH 136 tester. The hybrid between R-8 (102) and RAHH 136 recorded $2420.64 \mathrm{~kg}$ per ha.

For pop II, overall dissimilarity indices ranged from 39 to 57 per cent. The highest dissimilarity coefficient was noticed between the R-15 (136) and RAHH 102 (T2) with 57 per cent dissimilarity coefficient. The cluster analysis and dissimilarity coefficients revealed that the R-15 (136) line was far distinct to the RAHH 102 tester. The hybrid between R-15 (136) and RAHH 102 recorded $2388.89 \mathrm{~kg}$ per ha. 
Table.1 Correlation between the genetic diversity (through RAPD) and field performance of crosses

\begin{tabular}{|c|c|c|c|c|c|c|}
\hline $\begin{array}{l}\text { SL } \\
\text { No }\end{array}$ & $\begin{array}{l}\text { F4 lines of } \\
\text { RAHH-102 }\end{array}$ & $\begin{array}{c}\text { Genetic } \\
\text { Distrance } \\
\text { from C and D } \\
\text { (Parents of } \\
\text { RAHH-136) }\end{array}$ & $\begin{array}{c}\text { Field } \\
\text { performance of } \\
\text { derived F1's } \\
\text { between lines } \\
\text { and Tester } \\
\text { (RAHH-136) } \\
\text { SCY }(\mathrm{Kg} / \mathrm{ha})\end{array}$ & $\begin{array}{l}\text { F4 lines of } \\
\text { RAHH-136 }\end{array}$ & $\begin{array}{c}\text { Genetic } \\
\text { Distance } \\
\text { from A and } \\
\text { B (Parents } \\
\text { of RAHH- } \\
\text { 102) }\end{array}$ & $\begin{array}{c}\text { Field } \\
\text { performance of } \\
\text { derived F1's } \\
\text { between lines } \\
\text { and Tester } \\
\text { (RAHH-102 } \\
\text { SCY (Kg/ha) }\end{array}$ \\
\hline 1 & R-1 (102) & 0.45 & 2115.74 & R-1 (136) & 0.42 & 2095.24 \\
\hline 2 & R-2 (102) & 0.42 & 1086.64 & R-2 (136) & 0.39 & 2817.46 \\
\hline 3 & R-3 (102) & 0.42 & 1883.6 & R-3 (136) & 0.4 & 2035.05 \\
\hline 4 & R-4 (102) & 0.42 & 2191.14 & R-4 (136) & 0.42 & 1536.38 \\
\hline 5 & R-5 (102) & 0.48 & 2488.09 & R-5 (136) & 0.46 & 2206.35 \\
\hline 6 & R-6 (102) & 0.4 & 1832.01 & R-6 (136) & 0.51 & 2132.94 \\
\hline 7 & R-7 (102) & 0.5 & 2316.14 & R-7 (136) & 0.35 & 1906.74 \\
\hline 8 & R-8 (102) & 0.6 & 2420.64 & R-8 (136) & 0.59 & 2076.72 \\
\hline 9 & R-9 (102) & 0.48 & 2135.58 & R-9 (136) & 0.46 & 1780.43 \\
\hline 10 & R-10 (102) & 0.53 & 2021.82 & R-10 (136) & 0.53 & 1851.85 \\
\hline 11 & R-11 (102) & 0.49 & 2366.4 & R-11 (136) & 0.53 & 2236.78 \\
\hline 12 & R-12 (102) & 0.58 & 2005.29 & R-12 (136) & 0.55 & 2240.08 \\
\hline 13 & R-13 (102) & 0.45 & 2167.99 & $\mathrm{R}-13$ (136) & 0.41 & 1583.33 \\
\hline 14 & R-14 (102) & 0.5 & 2220.9 & R-14 (136) & 0.56 & 2396.83 \\
\hline 15 & R-15 (102) & 0.41 & 2210.98 & R-15 (136) & 0.57 & 2388.89 \\
\hline 16 & R-16 (102) & 0.56 & 2030.43 & R-16 (136) & 0.53 & 2391.54 \\
\hline 17 & R-17 (102) & 0.47 & 2351.85 & R-17 (136) & 0.43 & 1964.29 \\
\hline 18 & R-18 (102) & 0.44 & 2929.9 & R-18 (136) & 0.43 & 1941.8 \\
\hline 19 & R-19 (102) & 0.48 & 1903.44 & R-19 (136) & 0.48 & 2200.53 \\
\hline 20 & R-20 (102) & 0.4 & 2314.82 & R-20 (136) & 0.39 & 2246.03 \\
\hline 21 & R-21 (102) & 0.53 & 2355.82 & R-21 (136) & 0.53 & 2294.31 \\
\hline 22 & R-22 (102) & 0.49 & 2590.61 & R-22 (136) & 0.46 & 1414.02 \\
\hline 23 & R-23 (102) & 0.39 & 1917.99 & R-23 (136) & 0.4 & 2170.64 \\
\hline 24 & R-24 (102) & 0.47 & 1256.61 & R-24 (136) & 0.45 & 1539.68 \\
\hline 25 & $\mathrm{R}-25$ (102) & 0.51 & 2803.73 & R-25 (136) & 0.51 & 1148.38 \\
\hline 26 & R-26 (102) & 0.39 & 2582.01 & R-26 (136) & 0.41 & 1710.32 \\
\hline & Correlation & \multicolumn{2}{|c|}{0.178} & Correlation & \multicolumn{2}{|c|}{0.191} \\
\hline
\end{tabular}


Plate.1 RAPD pattern in R4 populations of RAHH-102 and RAHH-136 along with their parents

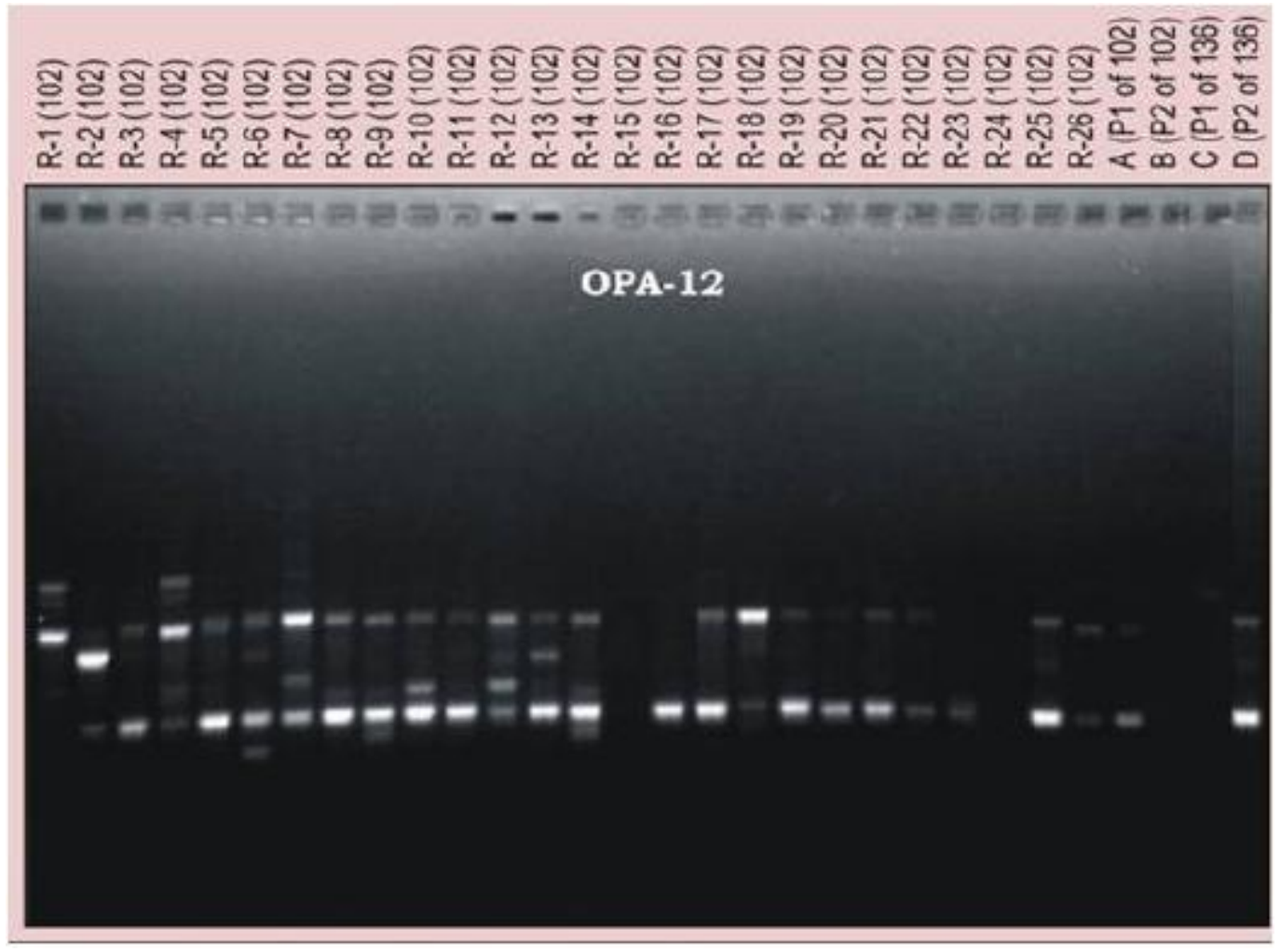

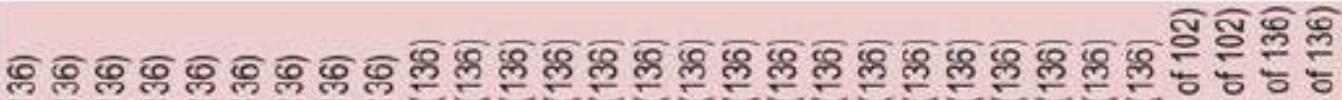
EE ㄱำ

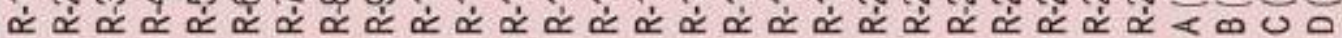

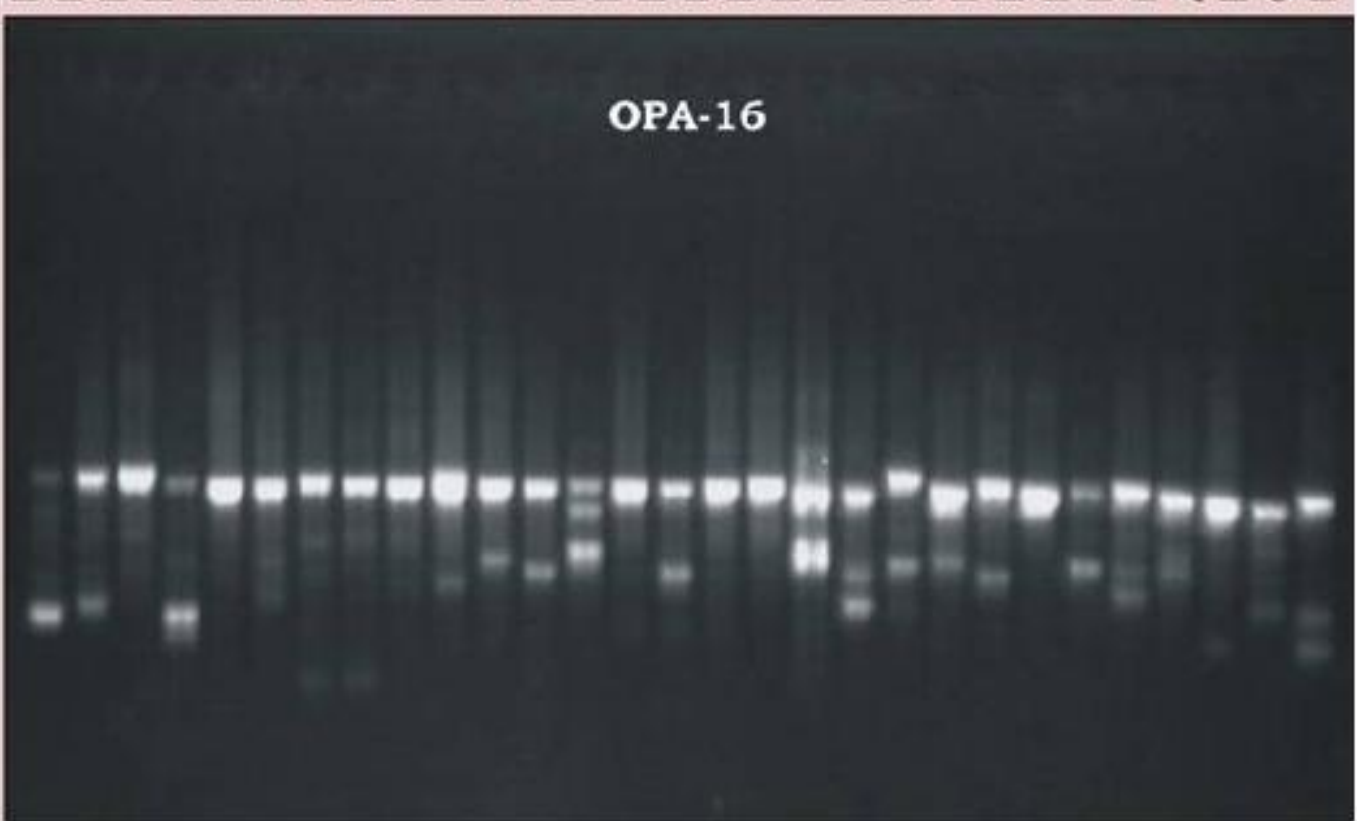


The correlation between the genetic distances matrix and the heterosis matrix was low $(\mathrm{r}=$ 0.178 and 0.199) (Table 1) for both populations and non-significant, or in other words, the genetic distances among parental lines is not related with the heterosis of their hybrids. It was observed that parental lines with smaller divergence had low values of heterosis (Lee et al., 1989). However, the limited genome coverage or the possibility that the molecular markers used are not close enough to the genes controlling seed cotton yield in cotton, did not permitted to extract final conclusions about the relationship between genetic distance among parents and the heterosis of their F1s. Similar results have been obtained in maize (Melchinger, 1990 and Dudley et al., 1991). Also, Martin et al., (1995) and Barbosa- Neto (1996) reported low correlations between genetic distances and heterosis in wheat.Charcosset et al., (1991) indicates that the detection of molecular markers which are not close to the genes responsible for the assayed trait may decrease the correlation between genetic distance and heterosis. Bernardo (1992) mentions that is essential to identify a specific marker related to the segments of the genome which determine the expression of the traits of interest to find a high correlation between genetic distance and heterosis. It may be expected that genetic distances, calculated using molecular markers, will become a useful way to predict heterosis until genes controlling important traits are placed on highly saturated genetic linkage maps and the adequate markers, those strongly linked can be chosen to calculate the genetic distance.

Concluded of the study is as follows:

In general, the correlation between genetic distances through RAPD among parents and the heterosis shown by their hybrids had no significance and may be because the molecular markers used to calculate genetic distances are not linked to the genes controlling seed cotton yield hence an effort has to be made to calculate the genetic distances between parents used for hybridization by using the molecular markers which are tightly linked to the morphological markers.

\section{References}

Barbosa-Neto, J. F., Sorrells, M. E. and CISAR, G., 1996, Prediction of heterosis in wheat using coefficient of parentage and RFLP based estimates of genetic relationship. Genome, 39 : 1142-1149.

Bernardo, R., 1992, Relationship between single cross performance and molecular markers heterozygosity. Theoretical and Applied Genetics, 83 : 628-634.

Cheres, M. T., Miller, J. F., Crane, J. M. and JNAPP, S. J., 2000, Genetic distance as a predictor of heterosis and hybrid performance within and between heterotic groups in sunflower. Theoretical and Applied Genetics, 100 : 889-894.

Chorcosset, A., Lefort-Buson, M. and GALLAIS, A., 1991, Relationship between heterosis and heterozygosity at marker loci : A theoretical computation.Theoretical and Applied Genetics, $81:$ 571-575.

Dhillon, B. S., 1991, Alternate recurrent selection of S1 and half-sib families for intra population improvement. Maydica, 36 : 45-48.

Dudley, J. W., Saghai-Maroof, M. A. and RUFENER, G. K., 1991, Molecular markers and grouping of parents in maize breeding programme. Crop Science, 31: 718-723.

Godshalk, E. B., Lee, M. and Lamkey, K. R., 1990, Analysis of relationship of restriction fragment length polymorphism with agronomic performance of maize.Theoretical and Applied Genetics, $80: 273-280$.

Gutierrez, O. A., Basu, S., Saha, S., Jenkins, J. N., Shoemaker, D. B., Chetham,C. L. and Mccarty, Jr. J. C., 2002, genetic distance among selected cotton genotypes and its relationship with F2 performance. Crop 
Science, 42 : 1841-1847.

Lanza, L. B., Souza, Jr. C. L., Ottoboni, L. M. M., Viera, M. L. K. and Souza, A. P., 1997, Genetic distance of inbred lines and prediction of maize single cross performance using RAPD markers. Theoretical and Applied Genetics, 94 : 1023-1030.

Lee, M., Godshalk, E. B., Lamkey, K. R. and Woodman, W. L., 1989, Association of restriction fragment length polymosphisms among maize inbreds with agronomic performance of their crosses. Crop Science, 29 : 1067-1071.

Liu, X. C. and Wu, J. L., 1998, SSR heterogenic patterns of parents for making and predicting heterosis in rice breeding. Molecular Breeding, 4 : 263-268.

Martin, J. M., Talbert, L. E., Lanning, S. P. AND BLAKE, N. K., 1995, Hybrid performance in wheat as related to parental diversity. Crop Science, 35 : 104108.

Melchinger, A. E., 1990, use of molecular markers in breeding for aligogenic disease resistance. Plant Breeding, 104: 1-19.

Melchinger, A. E., 1993, Use of RFLP markers for analysis of genetic relationships among breeding materials and production of hybrid performance, pp. 621-628.

Rohlf, F. T., 1998, NTSYS-PC numerical taxonomy and multivariate analysis, version 2.0. Applied Biostatics Inc., new York.

Saghai-Maroof, M. A., Soliman, K. M., Jorgensen, R. A. and Allard, R. W., 1984, Ribosomal DNA spacer length polymorphism in barley: Mendelian inheritance, chromosomal location and population dynamics. Proceedings of
National Academy of Sciences, USA, 81 : 8014-8018.

Smith, O. S., Smith, J. S. C., Bowen, S. L., Tenbory, R. A. and Wall, S. T., 1990,Similarities among a group of elite maize inbreds as measured by pedigree $\mathrm{F} 1$ grain yield, grain yield heterosis and RFLPs. Theoretical and Applied Genetics, $80: 833-840$.

Soregaon, C. D., 2004, Studies on genetic introgression in interspecific crosses of cotton.M. Sc. (Agri.) Thesis, University of Agricultural Sciences, Dharwad

Williams, J. G. K., Kubelik, A. R., Livak, K. J., Rafalski, J. A. and Tingey, S. V.,1990, DNA polymorphism amplified by arbitrary primers are useful as genetic markers. Nucleic Acids Research, 18 : 6531-6535.

Xiao, J., Li, J., Yuan, L., Mccouch, S. R., TANKSLEY, S. D., 1996, Genetic diversity and its relationship to hybrid performance and heterosis in rice as revealed by PCR-based markers. Theoretical and Applied Genetics, 92 : 637-643.

Zhang Jinfa, Deng, Zhong and Sunhizhong, 1994, Heterosis and combining ability in interspecific crosses between Gossypium hirsutum L. $\square$ Gossypium barbadense L. Journal of Huazhong Agricultural University, 13 : 9-14.

Zhao, M. F., Li, X. H., Yang, J. B., Xu, C. G., HU, R. Y., Liu, D. J. and Zhang, Q., 1999,Relationship between molecular marker heterozygosity and hybrid performance in intra and inter sub specific crosses of rice. Plant Breeding, 118: 139144.

\section{How to cite this article:}

Somashekhar, S. S. Patil and Patil, S. A. 2020. Molecular Diversity in Predicting Hybrid Performance in Cotton. Int.J.Curr.Microbiol.App.Sci. 9(01): 2449-2455.

doi: https://doi.org/10.20546/ijcmas.2020.901.279 